\title{
Cultura e Pedagogia: lições da espacialidade revolucionária de Frank Gehry
}

\author{
Marisa Vorraber Costa' \\ 'Universidade Luterana do Brasil (ULBRA), Canoas/RS - Brasil
}

RESUMO - Cultura e Pedagogia: lições da espacialidade revolucionária de Frank Gehry ${ }^{1}$. O artigo, resultante de pesquisas que investigam as conexões entre cultura e pedagogia, apresenta uma discussão sobre possibilidades oferecidas pela arquitetura para se pensar as movimentações intelectuais inspiradas no pensamento pós-estruturalista. O foco é o documentário Esboços de Frank Gehry, de Sydney Pollack. Discute-se a textualidade predominantemente visual de formas contemporâneas de ocupação do espaço urbano, a linguagem e as operações criativas da arquitetura de Gehry. Entende-se que vasculhando os limites da linguagem, artistas, assim como pesquisadores, remexem os limites do nosso mundo e nos ensinam a revolucionar a vida a cada dia.

Palavras-chave: Pesquisa Pós-Estruturalista. Arquitetura e Pedagogia. Cultura e Pedagogia. Cinema e Educação. Frank Gehry.

ABSTRACT - Culture and Pedagogy: lessons from the revolutionary spatiality of Frank Gehry. The article, emerging from researches that investigate the connections between culture and pedagogy, introduces a discussion about possibilities offered by architecture to reflect on intellectual movements inspired by post-structuralist thought. The analysis focus is Sidney Pollack's documentary Sketches of Frank Gehry. The prevalent visual textuality of contemporary ways of using urban space, Frank Gehry's language and his creative architectural operations are discussed. It is understood that while searching for the limits of language, artists, as well as researchers, rummage the limits of our world and teach us to revolutionize life on a daily basis.

Keywords: Post-Structuralist Research. Architecture and Pedagogy. Culture and Pedagogy. Cinema and Education. Frank Gehry.

Educação \& Realidade, Porto Alegre, v. 39, n. 1, p. 163-180, jan./mar. 2014. 
Gehry invites his guests to use this environment to become their own hosts. He invites his guests to shape their own experiences of this building in ways that allow them to both find and create their own learnings (Ellsworth, 2009, p. 72, sobre o Stata Center, obra de Frank Gehry para o MIT).

\section{Introdução}

Este artigo discute possibilidades oferecidas pela arquitetura contemporânea para se pensar as movimentações intelectuais inspiradas no pensamento pós-estruturalista ${ }^{2}$. Seu foco principal é a obra de Frank Gehry, especialmente na aproximação oportunizada pelo documentário Esboços de Frank Gehry ${ }^{3}$, de Sydney Pollack (2005), produção que nos coloca face a face com uma tentativa de esmiuçar a inventividade, de compreender o processo de criação. $\mathrm{O}$ estudo tomou corpo em etapa recente de um programa de pesquisa que venho desenvolvendo há alguns anos sobre as conexões entre cultura e pedagogia. Nele se entendem as pedagogias contemporâneas como um traço, como marca de um contínuo investimento, de uma incessante operação sobre todos os aspectos e âmbitos da vida dos sujeitos, o que faz de cada um de nós agentes em incessante atuação com os saberes. Tal programa de pesquisa filia-se a uma matriz de inteligibilidade que permite ver e compreender o mundo e a experiência contemporâneos como profundamente marcados por condições peculiares, imbricadas e implicadas no que tem sido designado por analistas da cultura como "condição pós-moderna", expressão utilizada, dentre outros, por Lyotard (1988) e Harvey (1993). Diz respeito a mudanças substantivas e profundas nas formas de vida verificadas ao longo do século XX. Uma plêiade de alterações que definem os contornos de experiências existenciais diversas e desencaixadas do horizonte construído sob a égide do mundo moderno da ordem, da segurança, da estabilidade, do "sonho da pureza", como a ele se refere Bauman (1998).

Nesse novo panorama em que se constituem as subjetividades de hoje e no qual se encaixam tensamente homens e mulheres moldados por outra ordem, chama atenção a proeminência do visual, a centralidade e o poder das imagens (Mirzoeff, 1998; 1999; Rose, 2001). Isso se destaca especialmente nas emergentes e variadas possibilidades de visibilidade e na ampla circulação de imagens oportunizadas pelas novas tecnologias de comunicação e informação, mas não exclusivamente por elas. Esboça-se também nas formas revolucionárias de ocupação do espaço urbano, e não é por acaso que as primeiras teorias do pósmoderno $^{4}$ vão surgir na arquitetura nos meados da segunda metade do século XX, um campo em que arte e sofisticados recursos técnicos e tecnológicos convergem em edificações que fazem da arquitetura um espetáculo visual. Assim como aparecem edifícios que contam histórias - alguns hotéis da Disney e de Las Vegas, por exemplo -, há outros, como o Museu Guggenheim de Bilbao, projetado pelo conhecido arquiteto contemporâneo Frank Gehry ${ }^{5}$, em que o próprio prédio - uma edi- 
ficação espetacular revestida de titânio - é a obra de arte. A par de ser uma profunda mudança cultural, uma condição existencial ímpar, um novo horizonte filosófico, artístico, sociológico e econômico, o pós-moderno, afirma Featherstone (1995), transformou-se em uma influente e poderosa "imagem cultural" e, como ressalta Manguel, "[...] as imagens, assim como as palavras, são a matéria de que somos feitos” (2001, p. 21).

Já há algum tempo percebi, instigada em grande parte pelas análises de Jameson (1996), que a arquitetura pós-moderna pode ser uma porta de entrada para se pensar sobre o que Williams (1965) denominou "nova estrutura de sentimento". Jencks (1991) foi um dos primeiros a afirmar que os arquitetos pós-modernos eram os "precursores de uma nova sensibilidade". O conceito de pós-moderno invade a cena cultural da segunda metade do século passado com uma enorme capacidade de expressar os novos sentimentos que emergem nas várias dimensões da vida cotidiana em meio às novidades da sociedade das mídias, com ressonâncias para além da arte, da estética, da filosofia e da economia. O pós-moderno já carrega consigo, segundo Jameson, uma ideia de cultura em que a fusão desta com a economia está de antemão contemplada, assim como se expressa em uma nova textualidade predominantemente visual. Isso talvez explique o "apetite pela arquitetura" que irrompe, inicialmente nos Estados Unidos, mas em seguida em numerosas metrópoles do mundo, o que, segundo Jameson (1996, p. 121), sugere "um apetite pela fotografia" já que "[...] muitos edifícios pós-modernos parecem ter sido projetados para serem fotografados, pois só em fotos ostentam sua existência brilhante e sua realidade [...]".

No intento que aqui realizo de pensar o trabalho intelectual pósestruturalista contemporâneo voltando-me à linguagem e às operações criativas da arquitetura, tomo como foco a obra de Frank Gehry ${ }^{6}$, e para isso recorro, particularmente, mas não exclusivamente, ao instigante documentário de Sydney Pollack (2005), Esboços de Frank Gehry, a meu ver, uma produção sob medida para se refletir sobre pedagogia e processos de pesquisa. À semelhança do processo criativo do artista, a pesquisa pós-estruturalista é do tipo que produz mudanças na interioridade, que desinstala certa racionalidade e suas formas de pensar e falar sobre as coisas. A escrita do pesquisador pós-estruturalista, assim como a revolucionária linguagem do arquiteto, exercitam tentativas de ressignificação, "de tornar dizível o indizível"7.

Um diálogo íntimo entre dois amigos artistas compõe o eixo narrativo do documentário. Um deles (Pollack) está fascinado pela visualidade criada pela lente e pela moldura da câmera, o outro (Gehry), apaixonado pela arte de inventar e transformar rabiscos sobre papel em edifícios monumentais. Seu percurso contempla incursões pela vida pessoal, assim como pelas obras do arquiteto, em uma aproximação não só pelo exterior, mas que perscruta seu avesso, alinhavos e tramas que costuram, na criação, visões de mundo, sentimentos, modos de operação e tecnologias ultra-avançadas. Rabiscos sobre papel conver- 
tidos em modelos tridimensionais tangíveis construídos com cartolina, papelão, fita adesiva, tesoura e cola eclodem, no final do século XX e neste início de século XXI, numa arquitetura revolucionária sem precedentes, considerada quase unanimemente por analistas especializados como a primeira a produzir nessa área uma experiência estética assentada sobre assombrosa desarmonia. Não está em questão aqui se este tipo de arquitetura corresponde àquilo que o cânone (ou o consen$s o$ ) arquitetônico entende como belo, habitável, ajustável à paisagem, com custo-benefício adequado etc., mas, antes, a produtividade de tais obras, o efeito que elas têm sobre nós e sobre este nosso tempo. É aí que talvez se possa dizer que entra em cena o sentimento de disrupção/ desconexão/desencaixe provocado pela pós-modernidade, e é nesta direção - não avaliativa da obra de Gehry, mas daquilo que ela pode nos provocar - que proponho que se pense a articulação entre cultura e pedagogia, especialmente no que tange a fazer pesquisa numa perspectiva pós-estruturalista.

\section{Uma Aproximação à Espacialidade Revolucionária de Frank Gehry}

Minha curiosidade pelo trabalho de Frank Gehry surgiu nos meados dos anos 1990, quando tomei contato pela primeira vez com as análises de Jameson (1996) sobre o pós-modernismo, apresentadas na conhecida obra Pós-Modernismo - a lógica cultural do capitalismo tardio, traduzida e publicada no Brasil em 1996. Nela há uma passagem em que Jameson reproduz uma entrevista com Gehry, realizada por Diamonstein ${ }^{8}$ e publicada inicialmente em 1980, a respeito da casa ${ }^{9}$ do arquiteto em Los Angeles - a mesma que é objeto de comentários no início do documentário de Pollack.

Naquela altura, eu já havia percebido que quem se interessasse pelo pós-moderno, pelo pós-modernismo e pelos debates sobre a pósmodernidade encontraria farto repertório informativo, problematizador, analítico e crítico nas discussões desenvolvidas no campo da arquitetura. Conforme mencionei no início deste texto, a materialidade de muito daquilo que consideramos indícios de transformações significativas na cultura, expressando "a profunda mudança na estrutura do sentimento" sobre a qual escreveu Williams (1965) nos anos 1960, ajudando a compor o que se convencionou denominar virada cultural, tem a ver com os embates que se travaram na arquitetura, enraizados numa contundente crítica aos equívocos do redesenvolvimento urbano do pós-guerra. De acordo com Portoghesi ${ }^{10}$ (1999), o declínio da ortodoxia modernista na arquitetura expressa recusa aos sistemas de composição da cultura intelectual da ciência urbana moderna, sustentada por axiomas jamais confrontados com as necessidades impostas pela materialidade da vida de pessoas de carne e osso. A ponto de Jencks (1996) ter datado como marco simbólico da morte do modernismo e passagem 
para o pós-modernismo - 15 de julho de 1972, às 15h32min - a ocasião em que foi dinamitado, por ser considerado um ambiente degradado e inabitável, o edifício modernista Pruitt-Igoe (em St. Louis, EUA) - uma versão premiada (concebida por Minoru Yamasaki) ${ }^{11}$ da "máquina para a vida moderna" de Le Corbusier.

Jameson (1996), em sua análise no capítulo em que trata da arquitetura, nos introduz na casa de Gehry por considerá-la “[...] um dos poucos edifícios pós-modernos que parecem ter alguma pretensão a uma espacialidade revolucionária" (p. 129). Jameson posiciona Gehry em um patamar destacado da arquitetura pós-moderna, uma vez que seu estilo teria pouco em comum com a frivolidade decorativa e com o acento narrativo dos projetos de alguns arquitetos como Michael Graves (hotéis da Disney, na Flórida), Charles Moore (Piazza d'Italia, New Orleans) ou Robert Venturi (Freedom Plaza, Washington DC). De acordo com Jameson (1996), o próprio Gehry teria afirmado estar pouco interessado em "contar histórias". Ele diz-se mais disposto a colocar mãos à obra e criar. Gehry fez da arquitetura uma arte da ocupação do espaço alavancada para fora do tempo. O predomínio do espaço sobre o tempo, o apagamento da duração e a fragmentação do tempo capturado em presentes eternos expressam-se em uma ocupação monumental do espaço. Eis algumas das nuances marcantes desse novo horizonte existencial ao qual venho me referindo. A partir desse ponto do livro de Jameson (1996, p. 129), quem passa a conversar com Gehry sobre sua casa de Los Angeles como uma obra de arte é Diamonstein.

Isso que Jameson (1996) chamou de "espacialidade revolucionária", ao referir-se ao trabalho de Gehry, diz respeito a como o arquiteto conseguiu fazer uma velha casa - "essa casinha engraçadinha [...] uma coisinha bem bonitinha"12 situada em Santa Mônica - dialogar com a nova edificação projetada para envolvê-la. Uma velha estética passando a fazer parte de um jogo novo, em que materiais transparentes e outros arranjos embrulhavam, mas deixavam visível e praticamente intacta, a casa antiga. A casa nova surge como se fosse uma camada, que junto com as janelas institui uma estética totalmente diferente da casa velha, alimentando uma constante tensão. Materiais baratos como metal corrugado, compensado, vidro e gradeados em forma de elos de correntes - esse o vocabulário do texto arquitetônico criado por Gehry - compuseram o invólucro, a casa nova.

Gehry (apud Jameson, 1996, p. 130) comenta na entrevista a Diamonstein que a casa é um tanto confusa, que gera certa desorganização no modo de viver nela. Ela sempre parece não estar concluída. A parte envidraçada, que une a velha e a nova casa, deixa tudo muito claro e visível, mas ao mesmo tempo confunde porque atenua as categorias de dentro e fora. Alguns efeitos da estrutura de metal corrugado, colocada em ângulos abruptos, inscrevem na casa signos de arte moderna. A claraboia da cozinha, um enorme cubo de vidro, de dia parece um espaço vazio e à noite um sólido que se projeta como um farol. "São os fantas- 
mas do cubismo", declara Gehry no documentário. Tudo isso, somado a outros tantos artifícios da edificação, resulta, conforme Jameson (1996, p. 135), em "ambiguidades perturbadoras". Não há destinações fixas e imutáveis para os espaços, não há acordos definitivos com funções estabelecidas. Jameson (1996) comenta as análises de Macrae-Gibson sobre a casa de Gehry, que estão no livro Secret Life of Buildings, em que esse autor afirma: "O olho humano ainda tem importância crítica no mundo de Gehry, mas o sentido de centro não tem mais seu valor simbólico tradicional" (Macrae-Gibson, 1985, apud Jameson, 1996, p. 136). Uma casa é para morar, mas se pode inventar formas de habitá-la que escapem ao convencionalmente estabelecido. Gehry relata na entrevista que muitos fotógrafos visitam a casa, e cada um, ao entrar, tem uma ideia diferente sobre como o lugar deveria aparecer, sobre como ele deve ser ocupado, sobre como se vive nele. E eles vão mudando o posicionamento da mobília e dos artefatos na casa, que Gehry sempre precisa rearranjar para si mesmo ao término das sessões de fotos. Ele conta também que sua mulher igualmente se declarava um pouco atrapalhada com tantas novas possibilidades que essa revolução espacial havia criado.

Um dos principais representantes do desconstrutivismo, que surge nos anos 1970 como movimento de recusa aos princípios construtivos vigentes, Gehry tanto subverte como combina surpreendentemente diferentes elementos da construção, diluindo fronteiras, misturando formas e materiais, rompendo com concepções cristalizadas de funções, usos e hierarquias. De acordo com Stungo (2000, p. 10), o escultor Richard Serra considera que a obra de Gehry "representa ruptura com toda a arquitetura contemporânea", sendo a primeira "a romper com a ortodoxia do ângulo reto". No documentário, Gehry relata ter crescido como um modernista, e um dos depoentes refere-se a ele como um "escultor cubista moderno", que usa na construção figuras e formas como ninguém fez antes. Seu gesto criativo conversa com legados culturais, num exercício intertextual que puxa fios de outros autores e tradições para com eles prosseguir em uma viagem ao desconhecido.

Diante do mantra moderno "decoração é um pecado", Gehry pergunta: "mas como se humaniza um edifício, sem usar decoração? Como torná-lo expressivo? Materiais precisam ser expressivos". E ele começa a criar com lixo, seja como inspiração, seja usando sucata. Uma alusão a isso é ressaltada no documentário quando, em resposta à pergunta sobre onde busca inspiração, Gehry refere-se a "espaços e texturas de uma cesta de lixo", e a câmera de Pollack nos conduz a enquadramentos dos meandros arquitetônicos intrincados e monumentais de alguns de seus prédios.

Gehry não só cria magistralmente, ele tensiona o estabelecido até o impensável. Como afirma um dos comentaristas no documentário de Pollack (2005): "Ele não só mudou o visual de uma época, ele remexeu as próprias leis da física". Em sua maneira de pensar sobre o lugar da arquitetura na cultura do novo milênio ele, afinal, acaba por entender e 
empregar a tecnologia avançada para criar uma arquitetura que é uma vibrante expressão do nosso tempo.

De certa forma, a vida no presente não se tornou apenas complexa; ela oferece, junto com isso, um amplo leque de possibilidades de fruição. A experiência estética passa a integrar de forma mais contundente, mais disseminada, mais efetiva e acessível o tecido urbano e as demais instâncias da existência contemporânea. A heterogeneidade de linguagens disponíveis hoje ajuda na composição de novas fontes de prazer e diversão. As cidades, os espaços públicos, cada vez mais compartilham essa dominante cultural (Jameson, 1996). Jencks (1984 apud Harvey, 1993, p. 271) faz uma afirmação instigante: "parece desejável que os arquitetos aprendam a usar essa heterogeneidade inevitável de linguagens. [...] [isso] é bastante divertido"; e completa: "O ecletismo é a evolução natural de uma cultura com escolha". Tal frase ressoa como um desafio e uma provocação no seio de sociedades em que certos grupos e instâncias, pelos poderes que detêm, pelos privilégios que concentram e pelas posições que ocupam, consideram-se legítimos definidores do cânone, daquilo que seria bom, mau ou ambíguo para todos.

Gehry projetou edifícios que vão além da ocupação do espaço, e o documentário evidencia as idiossincrasias desse artista subversor do traço linear que majoritariamente tem caracterizado a arquitetura. Conforme comenta Stungo (2000), há poucos edifícios que fazem as pessoas atravessarem o mundo para conhecê-los e admirá-los. O Taj Mahal e o Parthenon são dois deles; o Museu Guggenheim de Bilbao, projetado por Gehry, já faz parte desta seleta lista. Apenas nos dois primeiros anos após sua inauguração, mais de dois milhões de pessoas foram a esta pequena cidade às margens do rio Nervió, no norte da Espanha, para admirá-lo.

$\mathrm{O}$ arquiteto-artista questionador, dinâmico e empreendedor convive com o ser humano que fala de suas inseguranças e seus medos, de seus sonhos e seus projetos, de suas dúvidas e seus embates. Assim como no documentário, em inúmeras entrevistas Gehry procura descrever sua peculiar relação com a arte de edificar.

\begin{abstract}
Eu não procuro a coisa suave, a coisa bonitinha. Isso me irrita porque parece irreal. [...] um salão bonitinho, com belas cores, para mim é como um sundae de chocolate. Bonito demais. Sem relação com a realidade. A realidade, para mim, é bem mais rude; as pessoas se mordem (Stungo, 2000, p. 15).
\end{abstract}

Para criar condição propícia a uma aproximação com Gehry - o homem, o artista, o arquiteto -, foi também ele próprio quem recusou as inúmeras propostas anteriores para um documentário sobre seu trabalho e sua trajetória, e elegeu Pollack, outro artista, seu amigo, diretor polêmico assim como ele, que não conhecia nada de arquitetura, para levar a cabo este projeto. 
O documentário, produzido como um movimento de mútua invasão - Pollack adentra o universo arquitetônico de Gehry, e este, por sua vez, aventura-se um tanto tímido pelas sendas da visibilidade mediada pela câmera do cineasta -, nos surpreende pela simplicidade da narrativa clássica adotada por dois controvertidos gênios das artes: apresentação das obras, dados biográficos distribuídos ao longo do texto e um bate-papo reflexivo entre dois amigos mesclado com depoimentos de clientes, admiradores, projetistas da equipe de trabalho, auxiliares, terapeuta e críticos. O vídeo investiga, disseca, revira, celebra o processo de criação. De mirabolante, apenas o fascinante espetáculo arquitetônico inventado por Gehry e suas obras.

Poderíamos prosseguir falando longamente aqui acerca do genial e controvertido Frank Gehry. Suas obras, assim como o artista, são polêmicas e ambivalentes. Apesar do brilho, do sucesso, do espetáculo que proporcionam, nunca foram unanimidade. As críticas mais frequentes incidem sobre o elevado custo dos projetos e da manutenção e limpeza das edificações. Sublinham, também, o caráter experimental das inovações e os riscos. Outras referem que as obras não atendem ao requisito de conforto e durabilidade, e que alguns materiais de revestimento emanam muito calor. Algumas vozes denunciam que os museus projetados pelo arquiteto, mais atraentes e espetaculares do que as próprias obras de arte que expõem e abrigam, são edificados na contramão de suas funções. No documentário, uma das críticas diz respeito ao excesso: "Ele oferece demais aos seus clientes. Eles lhes pedem algo e ele logo lhes dá tudo". Como se vê, uma obra de impetuosa exuberância, que revolucionou a arquitetura levando as leis da física a limites impensáveis, que rompeu ortodoxias e revirou a estética de uma era, persiste controvertida e é alvo de contestações.

Aqui, então, impõem-se perguntas sobre o que pode interessar a nós, estudiosos da educação e da pedagogia, na arquitetura de Gehry. O que uma obra como a dele pode ter em comum com nossas preocupações como pesquisadores? O que aprendemos ao conviver com seu gesto de criação? Em que sentido pode ser interessante para nossos estudos essa aproximação com o processo criativo e com as obras de Frank Gehry? É claro que as possibilidades, aqui, são muitas e variadas.

\section{Pensar a Pesquisa com Frank Gehry}

Esboços de Frank Gehry é, sem dúvida, um artefato cultural bom para pensar. Ao nos permitir desfrutar o espetáculo visual proporcionado pelas obras de um artista tão magistral quanto polêmico, mas também para além da pura fruição, o documentário nos oferece incontáveis e variadas possibilidades de reflexão. Pollack com sua câmera nos conduz em um passeio com o arquiteto por suas obras, por seus modos de criar, compor, trabalhar, relacionar-se, produzir; por suas inseguranças, tensões e incertezas. Ao fazer isso, sob vários aspectos, a película 
apresenta elementos instigantes para refletir e discutir perspectivas, concepções, desafios da criação - e a pesquisa também não é isso? Antes de tudo, uma peculiar criação, que não se dá no vazio, mas é gestada em um universo de processos, práticas estabelecidas, discursos e lutas por sentido e significado. Criar é, entre infinitas possibilidades, invenção de combinações antes impensadas, outros modos de ver e compor, rearranjos que desintegram ordens e instauram novos espaços e patamares.

É assim que o documentário também nos permite refletir sobre impasses que se apresentam a quem se aventura por caminhos investigativos no que temos chamado de vertente pós-estruturalista. Certo modo de conceber pesquisa à revelia das ortodoxias, sem desconsiderar a possibilidade de, com humildade e coragem, inscrever-se nas margens, marcando outros lugares e formas de conceber, tensionando paradigmas. Quando Gehry fala sobre seus edifícios, ele os visualiza em meio aos demais que o circundam. A forma como um prédio inscrevese em um território, como altera a composição e o significado de uma região urbana causa-lhe perturbação, mas também fascínio. São, por exemplo, três impressionantes blocos de edifícios cambaleantes, revestidos de diferentes materiais (um de ladrilhos vermelhos, outro de aço inoxidável polido como espelho e outro de gesso branco) que revitalizaram uma exaurida área portuária às margens do Reno em Düsseldorf. "É preciso ser um bom vizinho", diz Gehry, manifestação cuja materialidade pode ser observada em inúmeros projetos, entre outros, o da Dancing House - edifício da embaixada da Holanda, às margens do rio Moldava, na parte histórica de Praga (1992-1994) - que parece bailar, seja pela fluidez da fachada principal do bloco voltado para o rio (que se contorce para permitir que os prédios antigos situados na outra esquina não percam suas vistas para o Moldava), seja pelo movimento das paredes e janelas, todas como se estivessem em balanço. Pela linguagem corporal que se estabelece entre as duas torres, recebeu também o apelido de Fred y Ginger ${ }^{13}$.

O documentário é também um modo de olhar o avesso dos processos de criação do artista-arquiteto, operando com isso já uma desconstrução que permite compreender aspectos centrais do pensamento pós-estruturalista. Como tal obra se tornou possível? Que prazeres, poderes, saberes, expertises se articularam em sua concepção? Para além da noção naturalizada da arte como genialidade individual, que indícios nos apontam para o trabalho de criação como bricolagem, deglutição do outro, mistura, hibridismo, contingência, provisoriedade? A obra de Gehry é seu idioma pessoal, produzido nos interstícios de outras escrituras, apropriando-se de elementos expressivos recolhidos aqui e ali, de imagens conceituais, de fragmentos, numa espécie de canibalismo como condição de possibilidade. Pensar e escrever, por sua vez, operações próprias do pesquisador, igualmente ocorrem nos entremeios do que outros pensaram e escreveram. Os textos são produzidos 
acumulando-se fragmentos de autores que nos ajudam a compor algo de outra forma, por outros ângulos. Pesquisadores inspirados no pensamento pós-estruturalista também recolhem fragmentos de textos ou imagens em suas obras e também recorrem à bricolagem, ao pastiche, não aprisionam a ambivalência e admitem a contingência e a provisoriedade de sua condição e de seus escritos.

\section{É Difícil Começar - medos e incertezas}

- Começar é difícil? Pergunta Pollack.

- Sim, responde o arquiteto, você sabe que é. É muito difícil, meio apavorante. Aí, limpo minha escrivaninha, faço anotações idiotas de forma a parecerem importantes. Vem então a rejeição, atrasos, negação. Sempre tenho medo de não saber o que fazer. É um momento terrível. Quando consigo começar, enfim, aí fico maravilhado! E penso: não é tão difícil!

Os sentimentos descritos por Gehry ressaltam a experiência de que o desafio de qualquer empreendimento criativo reside em conseguir enxergar/compor algo, desvencilhando-se de enquadramentos anteriores, procurando escapar das amarras do estabelecido e consagrado. Estranhar o que já se conhece ou jogar-se no desconhecido, pensar o que não se pensa. É um olhar indagador e aventureiro que está na origem da problematização que conseguimos compor e que vale a pena. Como a arte, a pesquisa não é um processo de mera constatação ou demonstração, mas de invenção. O mundo não está simplesmente aí para ser pesquisado. São indagações sensíveis, fecundadas por teorizações de igual teor, que conseguem, como um artista, construir um objeto para ser investigado. É também o olhar que o pesquisador deita sobre o mundo que faz emergirem perguntas instigantes, que ultrapassam concepções simplificadoras e, como tal, exauridas. Os prazos correndo, imenso acúmulo de leituras realizadas, incontáveis idas a campo, torturantes incertezas e uma aparentemente inexplicável paralisia são indícios dessa experiência que, a qualquer momento, pode eclodir em um jorro de possibilidades, em um manancial para o pensamento que inaugura outras concepções, outros encaixes, novamente expostos a crivos e especulações de todo tipo. Talvez justamente por isso, a maior satisfação de artistas como Gehry não seja a obra pronta, mas a renovada possibilidade de criar esboços. Da mesma forma, a pesquisa pós-estruturalista não pretende, afinal, desvendar definitivamente os mistérios do mundo e da vida, mas mostrar que conseguimos com nosso trabalho apenas hipóteses parciais e provisórias que nos oferecem uma segurança frágil e temporária.

Em outra passagem do filme Esboços de Frank Gehry, o arquiteto revela que às vezes indaga a si mesmo como pode lhe ter surgido uma ideia tão louca para certo projeto e, ainda mais, como pode ter tido a coragem de colocá-la em execução. Ele perde então o sono, imaginando o que poderá acontecer quando a obra começar a tomar corpo e, depois, quando mostrá-la ao mundo. Assim como Gehry, enquanto pesquisa- 
dores pós-estruturalistas nunca estaremos livres dos riscos e da incerteza implicados no cruzamento das fronteiras entre o que era considerado possível, pensável, e o impensado, imprevisível.

\section{Coragem, Aventura, Ambivalência - saltar fora da ordem}

Gehry se incomoda com as regras - algo central, particularmente, na arquitetura - e se empenha em duvidar delas, problematizá-las, dobrá-las, subvertê-las. E como um artista, arrisca-se. Mas não sem medos, conforme já comentei. Essa é mais uma aproximação entre as peculiaridades do trabalho intelectual dos investigadores da vertente pósestruturalista, e algo que decidi chamar aqui de movimentações criativas (sentimentos, embates, irritação, controvérsias, instabilidades, riscos) presentes nas atividades de criação artístico-arquitetônica narradas pelo arquiteto. Não é simples saltar fora da ordem, exige disposição, determinação, coragem, mas também outras ferramentas e métodos. Ele consegue misturar a liberdade da arte com algo concreto e intransponível - as leis da Física: afinal, "um edifício precisa ficar de pé!”. Ele também comenta que em seu trabalho há momentos (e houve muitos) em que precisou como que "saltar de um precipício" (intelectual, criativo), e aquilo acabou deixando-o muito feliz. Depois das comuns, frequentes e intermináveis incertezas, inseguranças, dúvidas, medos, nasce, como um filho, um edifício, que é um espetáculo e que funciona! Abdicar das certezas e arriscar-se parece ser a alternativa para se pensar para além de molduras prontas, que acabam se transformando em viseiras e nos permitem enxergar uma ínfima parte da conturbada, complexa e plurifacetada experiência humana. Nunca enxergaremos o todo, pois ele só existe em nossa imaginação, fruto da ilusão moderna de totalidade. Contudo é preciso explorar os limites, borrar as fronteiras, mudar os focos, trocar as lentes, movimentar a câmera, como faz Pollack no passeio em que nos conduz.

A certa altura, Gehry admitiu que a geometria descritiva não dava mais conta das exigências de seus projetos: uma mistura de técnica, ciência e arte, de desafios da física, de emoção estética; de movimentos leves, suaves, com amplitude e magnitude antes impensáveis. Conforme comentam no documentário, ele “[...] procura expressar sentimentos com objetos tridimensionais imensos".

Mitchell (2001, p. 354) salienta que a tendência dos arquitetos é "desenhar o que podem construir e construir o que podem desenhar". Gehry é um insurgente. Ele não dispensa os modelos físicos, tateáveis, o desenho, os esboços; ele reluta um pouco, mas rende-se e incorpora os computadores que simplificaram a modelagem digital das superfícies curvas, os cálculos de áreas e volumes, permitiram a visualização precisa de sombreados e sombras, assim como a realização de análises estruturais, térmicas e acústicas. A exploração exaustiva de sistemas e tecnologias computadorizadas levou-o também a novos usos de ma-

Educação \& Realidade, Porto Alegre, v. 39, n. 1, p. 163-180, jan./mar. 2014. 173

Disponível em: <http://www.ufrgs.br/edu_realidade> 
teriais e técnicas de construção, mas não sem riscos (Mitchell, 2001). Aqui, mais uma lição de Frank Gehry arquiteto: aprende-se a não negligenciar o desconhecido, mas procurar encontrar nele um manancial de novas possibilidades.

Com a tecnologia, foi possível dar formas esculturais aos prédios, desenvolver uma arte de construir edifícios cujo processo criativo está sempre no limite, não sem tensões e eivado de ambivalências - simplicidade, fragilidade, grandiosidade, vaidade, medo, coragem. Arquitetura? Escultura? E por que não pintura, quadros? Gehry já trabalhou com cerâmica, mas revela nunca ter tido coragem de enfrentar uma tela e uma paleta de cores. Pollack, entretanto, compôs uma sequência visual dos prédios, apresentando-os como se fossem imensas telas, admiráveis imagens pictóricas que se esboçam sobre as superfícies dos edifícios em jogos de cores, luz, sombras e reflexos. Tratar-se-ia de outra forma de pintura? Instável, contingente, efêmera e constantemente renovada? Gehry mistura cores e formas exatamente como faria um pintor. Todavia, suas telas são as faces cambiantes das edificações submetidas a efeitos de luz e sombras, a ângulos, reflexos, sinuosidades, enfim, uma arte pictórica de resultados sempre inesperados e esteticamente emocionantes.

Em outra passagem do documentário, um projetista declara ter sido crítico, difícil, levar a tecnologia para o processo criativo de Frank, à qual o arquiteto acabou por render-se. Ele reconheceu que o que pensava e inventava era mais arrojado e complexo do que ferramentas e técnicas disponíveis até aquele momento eram capazes de projetar e executar. Ao revolucionar o universo de possibilidades da arquitetura, tornou-se imperativo praticar uma revolução consigo mesmo. E ele não temeu mais esse enfrentamento. "Há um aspecto ameaçador em dar o salto, mas depois que você experimenta, que diz: - certo, tenho o direito! Bem, aí não dá mais para parar”. Nesse caso é bom lembrarmos que, quando Foucault $(1994 ; 2006)$ fala sobre os motivos que o impulsionaram em seus trabalhos, alude frequentemente a esse mergulho nos projetos em decorrência de uma curiosidade que produz uma transformação. "Quando escrevemos livros, desejamos que eles modifiquem inteiramente tudo aquilo que pensávamos e que, no final, nos percebamos diferentes do que éramos no ponto de partida" (Foucault, 2006, p. 289).

É o próprio Gehry quem nos conta sobre sua predileção pelos círculos de artistas, desde quando ainda era apenas um jovem arquiteto, em que tinha alguns amigos. Particularmente os admirava por não serem tão apegados à tradição e à história. Poucos arquitetos se misturavam com artistas, afirma, mas ele apreciava essa convivência com pessoas mais soltas e irreverentes.

Há muita inspiração em Frank Gehry para pesquisadores que se movimentam no terreno do pensamento pós-estruturalista - entregar- 
se à busca do conhecimento como a uma aventura, soltar o pensamento, perder-se, ouvir e deixar-se embalar. Ir ao limite da tensão entre medo, risco e diversão. Inventar, reinventando-se.

\section{Um Edifício não Precisa ser um Contêiner parecido com uma Caixa}

Gehry brincou com o cubismo em algumas de suas obras, resquícios de alguma convivência com manifestações artísticas que remontam ao início do século XX. Ele sempre repudiou o terror à mistura que caracterizou e ainda caracteriza a arquitetura até hoje (e não apenas ela). Fugindo dessa tendência, fez um pacto entre arte e arquitetura e se descreve como um obcecado pela conexão, por juntar ideias e criar uma nova linguagem. Declara ter se mantido sempre interessado em conexões, em juntar peças, e é ele próprio quem afirma ser essa talvez a única ideia que atravessou sua vida (Stungo, 2000). Parece que quando se experimenta a mistura, diz ele, já não se pode parar. Tal concepção é uma das que têm subsidiado novas perspectivas para problematizar e analisar a existência contemporânea sob a condição pós-moderna. Não há pensamento puro, todo o pensamento é híbrido, mas foram necessários aproximadamente 400 anos para que isso se tornasse dizível. Os estudos culturais são hoje um dos campos de pesquisa que se beneficiam do cruzamento e da ultrapassagem de fronteiras possibilitados pela desarticulação do sonho moderno da pureza.

Gehry é descrito no documentário por um de seus colaboradores como um misto de escritor e diretor, que concebe algo em uma folha em branco e o transforma em imagem visual tridimensional. Foi dessa forma que ele conseguiu mudar o visual de uma área como a arquitetura, extremamente conservadora. Philip Johnson ${ }^{14}$, um dos mais conhecidos e famosos arquitetos modernistas do século XX, considera Gehry o principal arquiteto do mundo de hoje. Conforme declarou a Pollack no filme, “[...] é impossível captá-lo em apenas duas dimensões”, chamando assim a atenção para as limitações enfrentadas pelo cineasta ao realizar um documentário sobre uma obra tão revolucionária, plurifacetada e polimórfica.

O fascínio do arquiteto pela articulação entre espaços, prédios e pessoas leva-o a decompor os projetos em partes, interligando blocos de formas completamente diferentes, raramente projetando uma edificação monolítica. Ele diz não a uma velha ordem e subverte categorias fixas como dentro e fora, instalando-as na ambivalência. A escadaria do Museu de Design Vitra (Alemanha) foi a primeira obra em que usou a tecnologia para conseguir projetar algo impensável na geometria descritiva - "Algo estranho, bagunçado, forças liberadas que encontram uma nova ordem”. E o Vitra está lá, belo, funcional, um híbrido emocionante. Uma experiência estética na desarmonia. Eis uma demonstração de que sempre é ainda possível ir além e pensar (e executar) o até então impensável.

Educação \& Realidade, Porto Alegre, v. 39, n. 1, p. 163-180, jan./mar. 2014. 175

Disponível em: <http://www.ufrgs.br/edu_realidade> 
Sobre o método, diz Gehry: "Começo sempre com os esboços e a partir deles montamos as maquetes. [...] feita a maquete, aí ficamos olhando para ela, até que nos irrite. Finalmente, tem uma aparência tão estúpida, que ficou ótima!". Essa atitude despretensiosa, irreverente e lúdica frente ao movimento intelectual criativo serve de inspiração para pesquisadores e desinstala a pesquisa do território da sisudez em que se tem entrincheirado. Há muitas formas de se produzir conhecimento e nada há que desqualifique a fruição como parte delas.

“E quando consideras que um projeto não está bem?", pergunta Pollack. Gehry responde que isso acontece quando tudo parece muito fácil para a equipe ou quando suspeitam que estejam entrando em um clichê. Nesses casos, diz, é preciso sofrer, agonizar um pouco. Hoje a equipe é uma marca de seus projetos, sem a qual já não conseguiria mais projetar. "Gosto de brincar nos projetos junto com a equipe. [...] Nossa comunicação é quase não verbal e é o senso de equipe que ajuda a ir até o fim". No caso das pesquisas em educação que se abrem para novas perspectivas analíticas, a movimentação parece seguir na mesma direção. Grupos de pesquisa constituem-se hoje em núcleos que inventam esboços cooperativamente, submetem as ideias a múltiplos crivos, cruzam hipóteses, puxam muitos e variados fios, criando redes de saberes. Mas não se trata aqui de coesão, de uníssono, e sim de coletivos onde há dissonâncias produtivas, que ajudam a ouvir e ver, a matizar e a fazer falar mais e mais diferenças.

Para Gehry, o importante é o processo de incubação. Um assistente relata que ele está sempre em volta das maquetes, sempre mexendo nelas. É como trabalhar com argila, que se vai moldando até encontrar algo em que nunca se pensou. Pode-se dizer que corresponde a uma atividade de pesquisa cujo movimento é exatamente este: a concepção do projeto com seu desenho, problema, objetivos e metodologia acontece num vaivém entre o campo de pesquisa e as ferramentas teóricas. Esse trânsito corresponde à incubação, na qual a modelagem acontece, em que o objeto de investigação (a obra de arte do pesquisador) é construído, tomando corpo com todas as suas nuances e especificidades.

\section{Não há Nada lá... está tudo aqui}

Gehry declara ter uma relação difícil com os prédios prontos. Como demoram muito para ser construídos, quando chega a um edifício acabado não lhe agrada perceber as coisas que não devia ter feito, assim como outras que parecem faltar. Percebe que há algo diferente neles e que não se via nas maquetes. Os reflexos da luz, que surgem quando eles estão prontos, a forma como ela bate no material, mostram como estão vivos e já não se pode mexer. Não há como voltar atrás.

As manifestações acerca do Guggenheim de Bilbao deixam claro seu prestígio como um dos edifícios mais impressionantes do nosso tempo. "Ele é a catedral mais importante do século XX", afirma um dos 
comentaristas no documentário. Outro diz que "[...] ele reúne muitas reminiscências, você entra e se sente em Luxor... Ele tem a escala do Egito". O diretor do museu lembra um jornalista que teria se referido ao Guggenheim como um objeto do espaço sideral que teria pousado em Bilbao há cem anos, algo alienígena, nada a ver com a cidade; porém, se o retirassem, não se poderia mais entender Bilbao sem ele. Pollack pede a Gehry que explique, diante do fenômeno Guggenheim, como pode dizer que tudo já foi feito, inventado, pensado em arquitetura: "Nunca vi um edifício igual a esse. Ele é sensual, musical, de onde vem tudo isso?”. $\mathrm{O}$ arquiteto responde tê-lo desenvolvido quando procurava uma forma de expressar sentimentos em objetos tridimensionais: "Vamos colocar algo aqui que leve a esse estado transcendental que se sente quando se faz arte". E é Phillip Johnson quem se refere ao museu como "uma visão do paraíso". A luz atinge outra forma, diz ele: "Minha nossa! De luz Gehry entende".

O cineasta pergunta se ele fica deprimido quando acaba uma obra. E Gehry responde que sim, que só relaxa um ano depois, após o teste do tempo, quando não houve vazamentos e as pessoas gostaram. Aí ele se distancia um pouco e consegue olhar para a obra. "Um prédio é como um filho, e eu os amo". "E você para para pensar que parte de você fez isso?", pergunta Pollack. Ao que Gehry responde:

Sim, penso nisso o tempo todo. Mas é como mágica, surge. E quando fico imaginando o que as pessoas vão pensar, quero me esconder sob as cobertas. Isso aconteceu com o Guggenheim de Bilbao. Eu nunca imaginei que ele seria o sucesso que é. De fato, antes de sua inauguração eu estava até um pouco constrangido e cheguei a pensar: "Meu Deus, como fui inventar isso?".

Até hoje, para Gehry, as obras em construção são suas preferidas, e justifica: "O edifício acabado tem segurança e é previsível. [...] Gosto de brincar à beira do perigo" (Stungo, 2000, p. 16).

\section{Revolucionar a Vida a cada Dia}

Pensar com a arquitetura de Gehry é uma experiência que produz também em nós uma revolução. Gehry não está apenas lá, em suas obras, ele está aqui, em cada um dos movimentos que fazemos como protagonistas da "longa revolução" que transformou a "estrutura do sentimento" - tal como descreveu Williams (1965) no final dos anos 1960 -, constituindo os seres desta nova era em que vivemos. É nesse sentido que suas obras e as movimentações que as tornaram possíveis podem ser pensadas como uma pedagogia, como aquele traço da cultura que engendra sujeitos. Bauman (1999, p. 287) afirma que "[...] a modernidade ainda está conosco. Ela vive como pressão de esperanças e interesses não satisfeitos sedimentados em instituições que se autorreproduzem [...]"; a universidade é uma delas. Apesar disso, o fato de hoje nos referirmos à modernidade como um projeto inacabado pode 
ser considerado uma expressão contundente de mudanças em nós mesmos. Parece que já saltamos fora e conseguimos olhá-la em suas múltiplas manifestações e efeitos sem nos confundirmos com ela. Nossa existência na condição pós-moderna submeteu nossa sensibilidade a razoabilidades discrepantes e incompatíveis com o monolítico mundo moderno da pureza e da ordem, sufocado de entulhos. Viver "no rastro”, como expressa Bauman (1999), pode significar turbulência, mas também panoramas mais amplos e nova compreensão. Armar outras perspectivas para ver e refletir pode nos ajudar, quem sabe, a "responder a uma urgência”, a articular nossas pequenas lutas diárias. Como nos sugere Foucault (1995, p. 256) em uma de suas entrevistas: "[...] nem tudo é ruim, mas tudo é perigoso. [...] a escolha ético-política que devemos fazer a cada dia é determinar qual é o principal perigo”.

Frank Gehry e os tensionamentos produzidos por suas obras contribuem de alguma forma para que nos libertemos, abdicando de certas pretensões, tornando mais leve e promissora, embora sempre incerta e eivada de inseguranças, a tarefa investigativa como criação. Vasculhando e remexendo os limites da linguagem, artistas, assim como pesquisadores, remexem os limites do nosso mundo.

O estilhaçamento da ideia de totalidade é um passo marcante em direção a ricas possibilidades para adentrar curiosamente pelas múltiplas faces da existência contemporânea, crivando verdades e certezas. Nem pessoas, nem coisas têm o seu lugar, mas podem habitar qualquer lugar, trocar de lugar; está liberta a ambivalência. Dentro e fora são categorias que geram ambiguidades perturbadoras, é melhor livrar-se delas, desprezar o horror à mistura e o sonho da pureza, permanecer em construção, ser obra inacabada, esquecer as generalizações e revolucionar a vida a cada dia.

Afinal, como conjectura Gehry no final do documentário, “Quando se é um jovem arquiteto, busca-se um tipo de perfeição impossível. Imagina-se algo que seria o ápice da carreira. Quando amadurece, você percebe que não há 'lá', que você não vai chegar 'lá'”.

Recebido em 07 de março de 2012 Aprovado em 01 de outubro de 2012

\section{Notas}

1 Agradeço a generosidade dos colegas e amigos Luis Henrique Sacchi dos Santos e Celso Vitelli, que se dispuseram a ler as versões finais deste texto e me ajudaram a livrá-lo de muitos problemas. Obviamente, a responsabilidade pelas ideias expostas é minha.

2 A expressão pensamento pós-estruturalistaé empregada com referência a aportes intelectuais trazidos por considerável conjunto de pensadores contemporâneos que criticam o racionalismo ao mesmo tempo em que mantêm compromisso com a racionalidade, agora totalmente subordinada à história. 
3 Título original: Sketches of Frank Gehry. Direção de Sydney Pollack. Sony Pictures Classics. EUA. 2005. 1 DVD (83 min.).

4 Obras expressivas são Learning From Las Vegas (1996, primeira edição em 1972), de Robert Venturi, Denise Scott Brown e Steven Izenour, e The Language of Post-Modern Architecture (1991, primeira edição em 1977), de Charles Jencks. Ambas são apontadas por Anderson (2005) como trabalhos iconoclastas, que contestam o modernismo na arquitetura, sendo Jencks quem teria tornado famoso no mundo da arte o termo pós-moderno.

5 Frank Gehry nasceu em Toronto, em 1929, e mudou-se para Los Angeles em 1947. Muitos de seus projetos são marcos da arquitetura contemporânea, entre eles o Walt Disney Concert Hall, em Los Angeles, o Vitra Design Museum, na Alemanha, e o Museu Guggenheim de Bilbao, na Espanha.

6 Considerado um dos fundadores do desconstrutivismo na arquitetura, em 1989, ganhou o Pritzker Prize (Hyatt Foundation), prêmio máximo da arquitetura mundial. Uma bibliografia alentada do e sobre o arquiteto pode ser encontrada em Friedman e Ragheb (2001).

7 Foram fonte de inspiração para este trabalho as anotações de aula do curso Escritas do Contemporâneo, ministrado em novembro de 2008, no Programa de Pós-Graduação em Educação da Ulbra, pelo professor Dr. Jorge Ramos do Ó, do Instituto de Educação da Universidade de Lisboa.

8 Entrevista constante da obra de Diamonstein, American Architecture Now, New York, 1980, p. 43-46 (cf. referenciado por Jameson).

9 Adquirida em 1978 e reformada em seguida, a casa vem passando por várias remodelações desde então.

10 Arquiteto, professor de História da Arquitetura na Escola Politécnica de Milão e diretor da seção de Arquitetura da Bienal de Veneza.

11 Arquiteto nipo-estadunidense, foi responsável, entre outros, pelos projetos das Torres Gêmeas, em Nova Iorque, e da Torre Picasso, em Madri.

12 Frase de Frank Gehry citada em Jameson (1996, p. 129).

13 Uma alusão à dupla de conhecidos bailarinos americanos Fred Astaire e Ginger Rogers.

14 Arquiteto norte-americano (1906-2005) considerado um dos pais da arquitetura moderna e um dos responsáveis pelos termos international style e arquitetura desconstrutivista. Philip Johnson recebeu, em 1979, o primeiro Prêmio Pritzker - considerada a mais importante láurea da arquitetura mundial.

\section{Referências}

ANDERSON, Perry. As Origens da Pós-Modernidade. Lisboa: Edições 70, 2005. BAUMAN, Zygmunt. O Mal-Estar da Pós-Modernidade. Rio de Janeiro: Jorge Zahar, 1998.

BAUMAN, Zygmunt. Modernidade e Ambivalência. Rio de Janeiro: Jorge Zahar, 1999.

ELLSWORTH, Elizabeth. Pedagogy's Time and Space. In: ELLSWORTH, Elizabeth. Places of Learning: media, architecture, pedagogy. London; New York: Routledge, 2009. P. 57-81.

Educação \& Realidade, Porto Alegre, v. 39, n. 1, p. 163-180, jan./mar. 2014.

Disponível em: <http://www.ufrgs.br/edu_realidade> 
FEATHERSTONE, Mike. Cultura de Consumo e Pós-Modernismo. São Paulo: Studio Nobel, 1995

FOUCAULT, Michel. História da Sexualidade II: o uso dos prazeres. Rio de Janeiro: Graal, 1994.

FOUCAULT, Michel. Michel Foucault entrevistado por Hubert L. Dreyfus e Paul Rabinov. In: RABINOV, Paul; DREYFUS, Hubert. Michel Foucault, Uma Trajetória Filosófica: (para além do estruturalismo e da hermenêutica). Rio de Janeiro: Forense Universitária, 1995. P. 253-278.

FOUCAULT, Michel. Uma Estética da Existência (entrevista). In: MOTTA, Manuel Barros da (Org.). Michel Foucault: ética, sexualidade, política. Rio de Janeiro: Forense Universitária, 2006. P. 288-293. (Coleção Ditos \& Escritos V).

FRIEDMAN, Mildred; RAGHEB, Fiona (Org.). Frank Gehry, Arquitecto. Bilbao: Guggenheim Bilbao, 2001.

HARVEY, David. Condição Pós-Moderna. São Paulo: Loyola, 1993.

JAMESON, Fredric. Pós-Modernismo: a lógica cultural do capitalismo tardio. São Paulo: Ática, 1996.

JENCKS, Charles. The Language of Post-Modern Architecture. New York: Rizzoli, 1991.

JENCKS, Charles. What is Post-Modernism? London: Academy Editions, 1996.

LYOTARD, Jean-François. O Pós-Moderno. Rio de Janeiro: José Olympio, 1988.

MANGUEL, Alberto. Lendo Imagens: uma história de amor e ódio. São Paulo: Companhia das Letras, 2001.

MIRZOEFF, Nicholas (Org.). The Visual Culture Reader. London; New York: Routledge, 1998.

MIRZOEFF, Nicholas. An Introduction to Visual Culture. London; New York: Routledge, 1999.

MITCHELL, William J. La Arquitectura de Frank Gehry: el fin de la era euclidiana. In: FRIEDMAN, Mildred; RAGHEB, Fiona (Org.). Frank Gehry, Arquitecto. Bilbao: Guggenheim Bilbao, 2001. P. 353-363.

PORTOGHESI, Paolo. Depois da Arquitetura Moderna. Lisboa: Edições 70, 1999. ROSE, Gillian. Visual Methodologies: an introduction to the interpretation of visual materials. London: Sage, 2001.

SKETCHES of Frank Gehry. Direção: Sydney Pollack. Sony Pictures Classics. EUA. 2005. 1 DVD (83 min.)

STUNGO, Naomi. Frank Gehry. São Paulo: Cosac \& Naify, 2000.

VENTURI, Robert; SCOTT-BROWN, Denise; IZENOUR, Steven. Learning From Las Vegas. Cambridge (EUA): The MIT Press, 1996.

WILLIAMS, Raymond. The Long Revolution. Harmondsworth: Penguin, 1965.

Marisa Vorraber Costa é licenciada em Filosofia e Doutora em Educação com estágios de pós-doutorado em universidades de Portugal, Espanha e Alemanha. Professora Titular em Ensino e Currículo da UFRGS (aposentada), é docente convidada do PPGEdu/UFRGS e também atua no PPGEdu/ Ulbra. Foi pesquisadora do CNPq durante 15 anos e tem investigado as conexões entre cultura e pedagogia. E-mail: vorrabercosta@gmail.com 